\title{
Iodine Concentration in Fodder Influences the Dynamics of Iodine Levels in Hen's Egg Components
}

\author{
Barbara Dolińska • Sebastian Opaliński • \\ Michał Zieliński • Katarzyna Chojnacka • \\ Zbigniew Dobrzański • Florian Ryszka
}

Received: 2 June 2011 / Accepted: 7 July 2011 /

Published online: 20 July 2011

(C) The Author(s) 2011. This article is published with open access at Springerlink.com

\begin{abstract}
In this study we determined the availability and accumulation of iodine in selected structures in hen's eggs: yolk, albumen, and eggshells. Iodine was administered as a yeast-derived biological complex mixed in standard fodder mix "DJ" to laying hens in their maximum egg yield period. The feeding period was sustained for 12 weeks, resulting in iodine enrichment in yolk and eggshells. These results suggest that iodine-enriched yeast can be added to fodder mix and premix (mineral-vitamin) given to monogastric animals such as poultry and pigs.
\end{abstract}

Keywords Iodine $\cdot$ Hen's eggs $\cdot$ Yolk $\cdot$ Albumen $\cdot$ Eggshell $\cdot$ Iodine $\cdot$ Accumulation $\cdot$ Content

\section{Introduction}

The best-known consequence of dietary iodine deficiency of a population is endemic goiter. The prevalence of this disease has been greatly reduced by gradual implementation of iodine supplementation programs by the World Health Organization (WHO). In spite of

B. Dolińska $(\bowtie) \cdot$ M. Zieliński

Department of Applied Pharmacy and Drug Technology, Medical University of Silesia, Kasztanowa 3, 41-200 Sosnowiec, Poland

e-mail: b.dolinska@biochefa.pl

S. Opaliński · Z. Dobrzański

Department of Animal Hygiene and Animal Welfare, Wrocław University of Environmental and Life Sciences, Wrocław, Poland

B. Dolińska • M. Zieliński • F. Ryszka

BIOCHEFA Pharmaceutical Research and Production Plant, Sosnowiec, Poland

K. Chojnacka

Institute of Inorganic Chemistry and Mineral Fertilizers, Wrocław University of Technology, Wrocław, Poland 
these efforts, iodine deficiency still exists even in developed countries, particularly among pregnant and breast-feeding women, which might result in miscarriages, newborn death, and intellectual deficiencies in children [1].

The thyroid gland begins functioning at the 11th week of fetal life. At that time even a marginal iodine deficiency can lead to impaired development of the nervous system, deafness, altered intellectual performance, lower IQ, increased spasticity, or ataxia in children [2].

In women iodine loss is increased during pregnancy or, since the iodine concentration in human milk is four times to that of the thyroid, by breast-feeding. In such cases a subclinical hypothyroidism often occurs, leading to thyroid nodule formation.

Animal models and demographic analysis show a connection between asymptomatic iodine deficiency and prevalence of thyroid, prostate, endometrial, and ovary cancers [3]. A similar phenomenon occurs in the mammary gland, which is extremely vulnerable to low iodine concentrations. Increased rate of mastopathy and mammary gland cancer is observed in regions affected by iodine deficiency [4]. Besides endocrine disorders, other iodine deficiency-induced diseases are less known. Children living in iodine-deficient areas show impaired immunity, decreased stress resistance, probably connected with iodine's antioxidant properties, or even vision impairment. It can be concluded that the scope of iodine deficiency-induced disorders is greater than previously thought and is reaching far beyond the impairment of thyroid hormone synthesis.

Since influence of iodine on the health of both mother and child is important, special care should be taken in order to provide sufficient iodine in the diet. Methods for increasing iodine content in foods have been in use for a long time. As other micro- and macronutrients, iodine is incorporated into yeast cells. Such enriched biological complexes are used to treat deficiencies in humans and animals. Household salt is enriched in iodine, animal fodder is iodized, and iodine is added to commercial processed foods [5-9]. Yeast and yeast-derived preparations are used directly in animal feeding or as a component of fodders, premixes, and probiotics [9].

Among the recommended foods that provide iodine in the diet, eggs play an important role. They are an inexpensive and easily available source of proteins, macro- and micronutrients, and minerals. Eggs are the best source of amino acids, fats, especially exogenous fatty acids, vitamins, and minerals $[10,11]$. Egg albumen is considered to be an international standard of amino acid composition according to FAO/WHO [10, 11].

For these reasons this work was carried out to determine the availability and accumulation of iodine in yolk, albumen, and shell of hen's eggs. Iodine in the form of a yeast-derived biological complex was added to a standard fodder mixture "DJ" to hens in their maximum egg yield period.

\section{Materials and Methods}

\section{Iodine-Enriched Yeast Complex}

The biological iodine complex derived from Saccharomyces cerevisiae grown on whey was purchased from the Pharmaceutical Research and Production Plant "Biochefa," in Sosnowiec, Poland. The iodine-enriched yeast had an iodine concentration of $666 \mathrm{ppm}$ with $28.5 \%$ total protein, $0.9 \%$ fat, $41.2 \%$ glutamic acid, $29.4 \%$ aspartic acid, and $24.8 \%$ lysine [8]. 


\section{Research Procedure}

The laying hens were 24-36 weeks old without symptoms of disease. Sixty hens were equally divided into the following study groups:

1. Controls $(K)$ : The hens $(n=20)$ were fed a standard fodder mix "DJ" for hens in the maximum egg production period. The daily feed intake was $100 \mathrm{~g}$ per hen, with a daily iodine intake of $186 \mu \mathrm{g}$.

2. Iodine group 1 (DJ1): The hens in this group $(n=20)$ were fed in the same manner than the controls, but the fodder was added with $500 \mathrm{~g}$ of iodine-enriched yeast per $1,000 \mathrm{~kg}$ fodder. The daily fodder intake per hen was $116 \mathrm{~g}$, representing $153 \mu \mathrm{g}$ iodine.

3. Iodine group 2 (DJ2): In this group $(n=30)$, the fodder was added with $1,000 \mathrm{~g}$ of iodine-enriched yeast per $1,000 \mathrm{~kg}$ of fodder, providing an iodine content of $2 \mathrm{mg} / \mathrm{kg}$ fodder. In this group the daily fodder intake per hen was $119 \mathrm{~g}$ and the daily iodine intake was $236 \mu \mathrm{g}$.

Thirty eggs were collected from each group at the beginning of the experiment and after $3,6,9$, and 12 weeks of supplementation. The yolks and albumens were separated, and the eggshells were ground prior to analysis. Based on the obtained results, the amount of iodine in yolk, albumen, and eggshells were calculated as the area under the iodine concentrationtime curve $\left(\mathrm{AUC}_{0-84 \text { days }}\right)$.

\section{Iodine Concentration Measurement}

The iodine concentration was measured using an ion-specific iodide electrode, type EI-01 from Hydromet, Poland. The electrode was calibrated using a series of iodide solutions of known concentration. The dependence between the molar iodide concentration and the value in the display was given by a regression equation:

$$
y=4 E-13 e^{2.303 x}
$$

where

$x$ - value in the display

$y$-molar iodide concentration

$e=2.718$

Analysis of the Results

The results are presented as the mean value $(x \pm \mathrm{SD})$ of 30 eggs. Significant differences were established by means of Student's $t$ test, setting the significance level at $p<0.05$. All calculations were performed using Excel (Microsoft) and Statistica for Windows 5.1 (StatSoft Inc.) software.

\section{Results and Discussion}

Figure 1 presents the changes of iodine concentration in egg yolk according to the amount of iodine added to the fodder. The initial iodine concentration in yolk was set as $100 \%$ for the three study groups. 
Fig. 1 Dynamics of changes of iodine content in yolk depending on the amount of ingested iodine

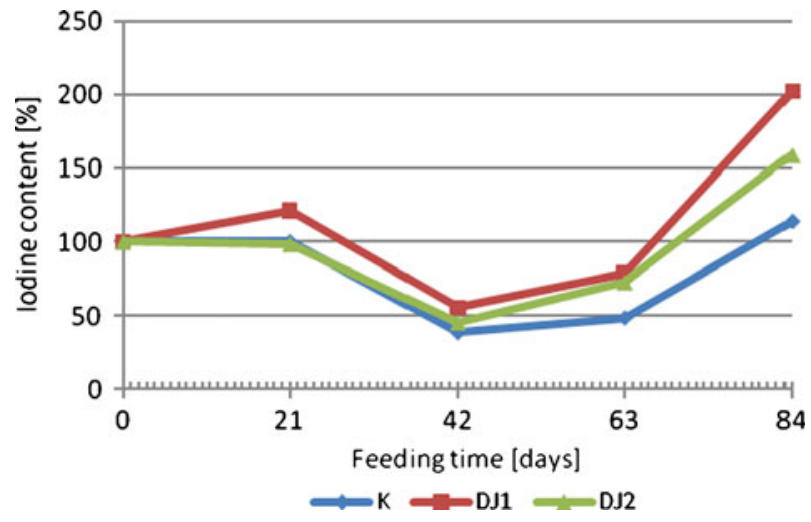

At the beginning of the experimental period, there were no significant differences of the iodine concentration among the three groups. After supplementation with iodine-enriched yeast, there were no increases of the iodine content in egg albumen. No significant differences were seen among the experimental groups DJ1 and DJ2 and the controls.

After 84 days of feeding, an increase of iodine concentration in yolks and eggshells was observed in the supplemented groups relative to controls. In yolks the iodine concentration was about $9.2 \mu \mathrm{g} / \mathrm{yolk}$. The iodine concentration in the controls remained unchanged during the experimental period.

Figure 2 presents the iodine concentration changes in eggshells depending on the amount of iodine added to the fodder. Figure 3 presents the process of iodine accumulation in the yolk throughout the course of the experiment ( $0-84$ days). Figure 4 shows the accumulation of iodine in the eggshells.

Independent from the amount of ingested iodine, at the sixth week of feeding, a 50\% decrease of its concentration was observed in yolk. After 9 weeks an insignificant increase of the iodine concentration was observed but it remained under the $100 \%$ threshold. The fluctuation of iodine concentration in yolk in the experimental groups was not statistically significant in comparison to the controls. On the 84th day of feeding in the hens with iodine-enriched fodder, a statistically significant increase in iodine concentration in yolk was observed.

The initial iodine concentration in eggshells $(\sim 5.85 \mu \mathrm{g} / \mathrm{shell})$ was also set as $100 \%$. The iodine concentration in eggshells increased in a time-dependent manner. The incorporation

Fig. 2 Dynamics of changes of iodine content in eggshell depending on the amount of ingested iodine

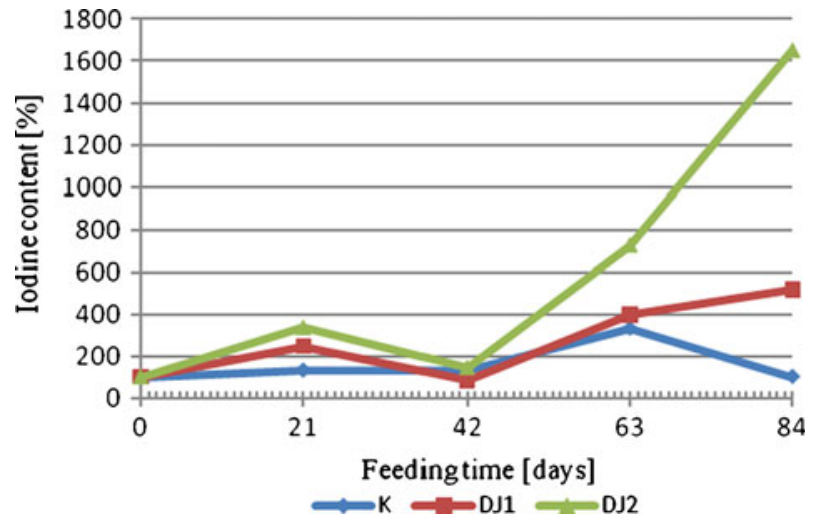


Fig. 3 Iodine accumulation in egg yolk depending on the amount of ingested iodine

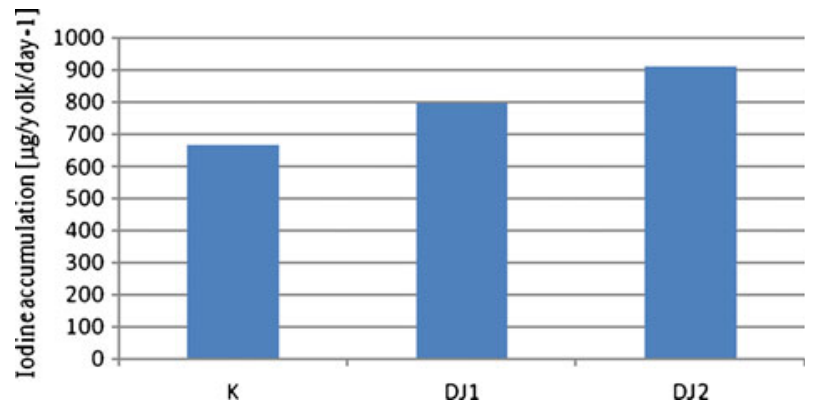

of iodine into eggshells in the 0-63-day supplementation period was not significantly different from that of the controls, but on the 84th day, there was a significant increase in iodine concentration in eggshells in the supplemented groups.

After 84 days of feeding, the area under the iodine concentration curve was $665.8 \mu \mathrm{g} /$ yolk/day ${ }^{-1}$ for the controls. Administration of $1 \mathrm{mg}$ iodine per $1 \mathrm{~kg}$ fodder caused an increase of iodine concentration in yolk by $19 \%$, to $793.3 \mu \mathrm{g} / \mathrm{yolk} / \mathrm{day}^{-1}$. Adding $2 \mathrm{mg}$ iodine per $1 \mathrm{~kg}$ fodder increased iodine concentration in yolk by $37 \%$, that is $910.4 \mu \mathrm{g} /$ yolk/day ${ }^{-1}$. The greatest accumulation of iodine was found in eggshells. These results indicate that iodine supplementation to laying hens during the maximum egg production period could be a simple method of increasing iodine concentration in egg yolk.

The calculated area under the iodine concentration-time curve was $6,972 \mu \mathrm{g} / \mathrm{eggshell} /$ day $^{-1}$. For the group supplemented with $1 \mathrm{mg}$ iodine per $1 \mathrm{~kg}$ fodder, the iodine concentration in eggshell increased 1.3-fold, to $9,118 \mu \mathrm{g} / \mathrm{shell} / \mathrm{day}^{-1}$. A twofold increase in iodine concentration in the fodder caused a twofold increase in eggshell iodine content, in total $1.424 \times 10^{4} \mu \mathrm{g} / \mathrm{shell} /$ day. The concentration of iodine in eggshells was 10 -fold higher than in the yolks of both controls and group DJ1 and 16-fold higher in the DJ2 group.

Eggshells are a novel, natural source of mineral nutrients. Ground eggshells could be a good source of highly bioavailable calcium and other elements including fluorine and strontium $[12,13]$. Eggshells are composed mostly of calcium carbonate $(90 \%)$, which as a supplement would efficiently increase bone density and decreases bone deterioration rate $[12,13]$. Various enzymes, hormones, and growth factors are also found in eggshells. The abundance of those substances is linked to its protective role and to antibacterial and antiviral properties that are crucial for the developing embryo. The results presented here suggest that iodine enrichment of fodder would result in significant increase of the iodine concentration in the eggshell.

Fig. 4 Iodine accumulation in eggshell depending on the amount of ingested iodine

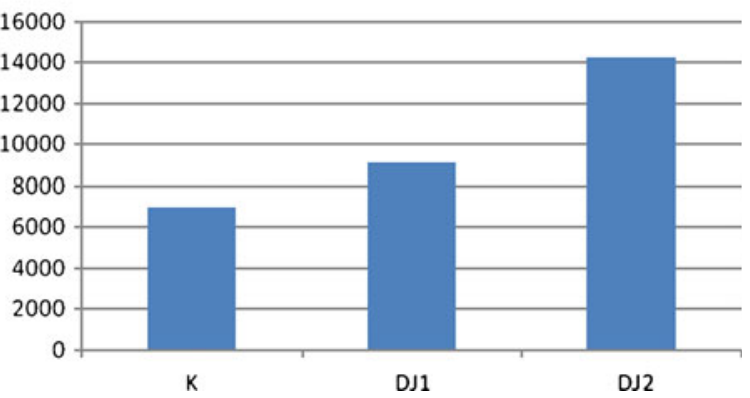




\section{Conclusions}

1. Feeding laying hens with iodine-enriched yeast results in iodine enrichment of the yolk and eggshell.

2. Iodine-enriched yeast can be used during fodder mix and premix production, especially for feeding of monogastric animals such as poultry and pigs.

3. The iodine concentration in egg yolk and shell is dose and time dependent. The iodine concentration in albumen remains unchanged even after 12 weeks iodine supplementation.

Acknowledgment This research was funded by The Ministry of Science and Higher Education (Project NN 209184836 ).

Open Access This article is distributed under the terms of the Creative Commons Attribution Noncommercial License which permits any noncommercial use, distribution, and reproduction in any medium, provided the original author(s) and source are credited.

\section{References}

1. Dunn JT, Delange F (2001) Damaged reproduction: the most important consequence of iodine deficiency. J Clin Endocrinol Metab 86:2360-2363

2. Zimmermann MB (2010) Symposium on geographical and geological influences on nutrition: iodine deficiency in industrialized countries. Proc Nutr Soc 69(1):133-143

3. Stadel BV (1976) Dietary iodine and risk of breast, endometrial, and ovarian cancer. Lancet 1:890-891

4. Aceves C, Anguiano B, Delgado G (2005) Is iodine a gatekeeper of the integrity of the mammary gland? J Mammary Gland Biol Neoplasia 10:189-196

5. Travnicek J, Kroupova V, Herzig I, Kursa J (2006) Iodine content in consumer hen eggs. Vet Med 51:93100

6. Haldimann M, Alt A, Blanc A, Blondeau K (2005) Iodine content of food groups. J Food Compos Anal 18:461-471

7. Hasler CM (2000) The changing face of functional foods. J Am Coll Nutr 5:499S-506S

8. Dolińska B, Zieliński M, Opaliński S, Korczyński M, Dobrzański Z, Ryszka F (2011) Optimization of the conditions of iodine incorporation to Saccharomyces cerevisiae yeast. Przem Chem 5:174-179

9. Linge P (2005) The use of probiotics and yeast derivatives in India. World Poult 10:12-15

10. Dolińska B, Wożniak D, Ryszka F (2009) Białka żółtka jaja kurzego, właściwości i zastosowanie. Farm Przegl Nauk 6:19-22

11. Kovacs-Nolan J, Phillips M, Mine Y (2005) Advances in the value of eggs and egg components for human health. J Agric Food Chem 22:8421-8431

12. Masuda Y (2005) Hen's eggshell calcium. Clin Calcium 1:95-100

13. Rovensky J, Stancikova M, Masaryk P (2003) Eggshell calcium in the prevention and treatment of osteoporosis. Int J Clin Pharmacol Res 2-3:83-92 